\title{
Knowledge and Attitudes of Young Adults Towards Donation of COVID-19 Convalescent Plasma and Its Therapeutic Properties
}

\author{
Lidia Perenc (D) \\ Ryszard Pęczkowski ${ }^{2}$ \\ 'Institute of Health Sciences, University \\ of Rzeszow, Rzeszow, 35-310, Poland; \\ ${ }^{2}$ Institute of Education, University of \\ Rzeszow, Rzeszow, 35-959, Poland
}

\begin{abstract}
Purpose: The aim of this study is to investigate the level of knowledge of the young adults towards the possible use of the convalescent plasma (CP) in the treatment of COVID-19 infection and their attitudes towards its donation.

Methods: Cross-sectional questionnaire was administered online to 1058 university students, representing 4 different colleges. The questionnaire included demographic data and 20 questions related to the knowledge and attitudes of respondents about possible use of the convalescent plasma in the treatment of COVID-19 infection and its donation. Comparative analyses were made using the Mann-Whitney and Kruskal-Wallis tests and the Spearman correlation coefficient.

Results: Significant relationships were found between dependent variables (level of knowledge and intensity of attitude) and gender, age, and student's college affiliation. There was no statistically significant correlation between dependent variables and respondents' social background and religious commitment. Studied young adults show a satisfactory knowledge relating to the therapeutic and preventive properties of the COVID-19 convalescent plasma. They also express a sufficient intensity of positive attitude towards CP donation.

Conclusion: This study confirms the need for appropriate health promotional campaigns and educational programs aimed at popularization of CP donation in the general public, which would increase the chances of involving more patients recovered from COVID-19 disease.
\end{abstract}

Keywords: COVID-19 convalescent plasma, knowledge, attitude, donation

\section{Introduction}

Currently, the world is going through a period of very serious crisis caused by the coronavirus pandemic (SARS-CoV-2), which has induced disturbances in almost all areas of life. The disease induced by this virus, popularly called COVID-19, causes acute inflammation of the respiratory system and is characterized by a high transmissibility and infection fatality rate (IFR) estimated at $0.68 \%$. ${ }^{1}$

The very first observations showed that exposure to SARS-CoV-2 does not cause infection in all people belonging to a given population, and not all infected people suffer from acute respiratory system inflammation. ${ }^{2}$ This variation in the course of infection and disease may depend on the individual's immune response. For these reasons, clinically, SARS-CoV-2 infection has been classified into two categories: mild and severe. ${ }^{2}$ There are many reasons to believe that the progression
Correspondence: Lidia Perenc

Email la.perenc@gmail.com 
of the disease depends on the genetic predisposition that makes the immune systems of different people react to infection in a specific way. ${ }^{3}$

In the face of the existing threats, the international scientific community is working intensively to develop an effective method of treating patients with COVID-19. In this context, high hopes are attached to passive and active immunotherapy strategies. As is known, specific active immunization can take place in a natural way, consisting in acquiring immunity after a specific infectious disease. It is also possible to generate specific immunity by artificial means, by administering a specified protective vaccination, according to the route and schedule of administration established by the manufacturer. The vaccine contains an antigen, specific to a particular microorganism, capable of producing an immune response and memory. ${ }^{4}$ In this respect, an advantage has the passive immunotherapeutic strategy of administering "ready-made" antibodies that modify the inflammatory response, thanks to the properties achieved during the previous immune reaction. ${ }^{5}$ An example of a passive immunotherapeutic strategy is convalescent plasma therapy, widely used in the treatment of patients suffering from SARS-CoV-2 infection. The observations to date show that it is regarded as an effective form of treatment used in many countries. ${ }^{6,7}$ However, there are some risks associated with the administration of $\mathrm{CP}$ that have been categorized as known and theoretical risks. The known risks include reactions against the plasma constituents and unintended infections induced by several infectious agents that might be present in the serum. The theoretical risks include phenomena like antibodydependent enhancement of infection, in which the severity of a viral disease is enhanced in the presence of specific antibodies. ${ }^{8}$ For example, more recent studies show that risk factors for patients with COVID-19 are concomitant hematological malignancies (HM), especially acute leukemia (AL), which are associated with the need to stay in intensive care units (ICU) and even with increased mortality in case of complications. ${ }^{9-11}$ Therefore, this group of patients should be of special concern during the ongoing COVID-19 pandemic. Nonetheless, it can be assumed that the number of patients treated with convalescent plasma (CP) will be much higher, which will increase the demand for donors in the longer term. ${ }^{12}$ This assumption is supported by the current trend in the development of the discussed pandemic. Recent studies on the characteristics of CP donors have shown significant differences compared to whole blood (WB) and plasma/platelet apheresis (SA) donors. The $\mathrm{CP}$ donors were more likely to be first-time and female donors than WB or SA donors. Also, CP donations had a higher rate of donor adverse reactions, deferrals, and product loss than SA donations. ${ }^{13}$ The cited authors concluded that improved knowledge of the characteristics of $\mathrm{CP}$ donors and donations could be used to guide donor retention strategies and in-production planning. Also, the establishment of a comprehensive database, including clinical and laboratory data from COVID-19 plasma donors, may be helpful in planning subsequent steps including convalescent plasma collection and much safer experimental and therapeutic interventions. ${ }^{14}$

Within the general population of Poles, young adults constitute a large group of potential blood plasma donors. In Poland, there is a lack of research assessing the knowledge, attitudes and behavior of this group of people with regard to the therapeutic role of $\mathrm{CP}$ and their motivation to be a donor. Recently performed research has focused on the analysis of the effectiveness of convalescent plasma for COVID-19 patients only. ${ }^{15}$ A closer look at young people's attitudes and the cognitive and motivational mechanisms underlying donor decisions can be helpful in inspiring these persons to donate blood plasma for therapeutic purposes. It seems that this is a sufficient argument to justify the purposefulness of research undertaken by the authors of this article.

\section{Materials and Methods Study Design}

It was a cross-sectional study conducted in four colleges belonging to the University of Rzeszow during the period of January-February 2021. The aim of the study was to investigate the knowledge, opinions and attitudes of the students towards possible use of the convalescent plasma in the treatment of COVID-19 infection and their willingness to its donation. Permission from the relevant authorities of the university was obtained before actual data collection.

\section{Participants}

The study sample consisted of 1058 students from the University of Rzeszow. For the selection of respondents, a purposive sampling technique was used to select the students from the College of Humanities, College of Medical Sciences, College of Social Sciences, and College of Natural Sciences. 


\section{Ethical Consideration}

This study was conducted in accordance with the Declaration of Helsinki. Ethical approval was granted by the Bioethics Commission of the University of Rzeszow (Resolution no. 01/02/2021). Participation was voluntary and anonymous (no personal identification was recorded), and confidentiality of the participants was ensured. They were informed that the data obtained were anonymous and will be utilized only for research purposes. Details about the study objectives were provided in the questionnaire instruction, and if the respondent returned the questionnaire, it indicated informed consent.

\section{Instrument}

The questionnaire used in the study contained 3 sections that contained dependent and independent variables. The first section contained sociodemographic characteristics. The second and third sections were related, respectively, to the measurement of the knowledge and attitudes of respondents about possible use of the convalescent plasma in the treatment of COVID-19 infection and its donation. Both the second and third sections contained 10 questions each. (An example of a question related to the knowledge section: 'Do you agree that, thanks to modern laboratory methods, the risk of transmission of blood-borne pathogens and the risk of serological conflict in practice do not exist in plasma transfusions?; An example of a question related to the attitude section: "Would you voluntarily donate blood plasma after recovery from COVID-19 if asked by an unknown person?"). The authors included the knowledge questions in the questionnaire based on the results of their previous research on knowledge and attitudes of young people towards organ donation and transplantation. ${ }^{16} \mathrm{~A}$ scoring mechanism was used in order to assess the overall knowledge level and attitude of the participant regarding $\mathrm{CP}$ donation. A score of 1 was given for each correct response and a score of 0 for a wrong response. Respondents with all correct responses get a maximum of 10 points, both in sections two and three. Statistical analysis of the data was based on each participant's total scores. The questionnaire was electronically administered to all participants to all participants via the university portal. This was due to the fact that during the COVID-19 pandemic, all classes at the university were conducted online. Out of 4000 persons included in the study (1000 for each college), 1058 respondents returned the completed questionnaires, which gives a response rate of $26.4 \%$.

\section{Statistical Analysis}

The analysis of quantitative variables was performed by calculating the mean, standard deviation, median and quartiles. The analysis of qualitative variables was performed by calculating the number and percentage of occurrences of each value. The comparison of the values of quantitative variables in two groups was performed using the Mann-Whitney test, and the values of quantitative variables in three or more groups using the Kruskal-Wallis test. Correlations between quantitative variables were analyzed using the Spearman correlation coefficient. A significance level of 0.05 was adopted in the analysis. Thus, all $\mathrm{p}$ values below 0.05 were interpreted as showing significant relationships. The analysis was performed in the R software, version 4.0.4.

\section{Results}

Table 1 shows sociodemographic characteristics of the study participants. Among the total of 1058 respondents, the largest group are students of the College of Social Sciences $(\mathrm{N}=391)$, followed by College of Medical Sciences $(\mathrm{N}=294)$, College of Natural Sciences $(\mathrm{N}=$ 213), and College of Humanities $(\mathrm{N}=160)$. The average age of the respondents ranged from 21.76 (College of Natural Sciences) to 23.04 years (College of Humanities). In this respect, the difference between the compared groups of respondents was not statistically significant $(p=0.272)$. Larger differences between them occurred in terms of the gender of the respondents. The percentage of women in particular groups ranged from $61.50 \%$ (College of Natural Sciences) to $80.31 \%$ (College of Social Sciences), and men from 19.69\% (College of Social Sciences) to $38.50 \%$ (College of Natural Sciences). In this case, the difference between the compared groups was statistically significant $(\mathrm{p}$ $<0.001)$. In the entire surveyed population, women accounted for $73.82 \%$, while men $26.18 \%$ only. Among all respondents, $54.16 \%(\mathrm{~N}=573)$ come from the rural social environment, and $45.84 \%(\mathrm{~N}=485)$ from the urban. The rural social environment was most often represented in the group of students of College of Natural Sciences $(65.73 \%)$, while it was the least frequent among students of College of Medical Sciences (45.58\%). The largest number of students from the urban environment was in the College of Medical Sciences (54.42\%), and the smallest number in the College of Natural Sciences (34.27\%). In this respect, the difference between the compared groups turned out to be statistically significant $(\mathrm{p}<$ 
Table I Sociodemographic Characteristics of the Studied Group

\begin{tabular}{|c|c|c|c|c|c|c|}
\hline \multicolumn{2}{|l|}{ Parameter } & \multirow{2}{*}{$\begin{array}{c}\begin{array}{c}\text { College of } \\
\text { Humanities }(\mathbf{N}= \\
\text { 160) }\end{array} \\
23.04 \pm 4.98\end{array}$} & \multirow{2}{*}{$\begin{array}{c}\text { College of Medical } \\
\text { Sciences }(\mathbf{N}=294) \\
22.62 \pm 4.72\end{array}$} & \multirow{2}{*}{$\begin{array}{c}\text { College of Natural } \\
\text { Sciences }(\mathbf{N}=213) \\
21.76 \pm 2.6\end{array}$} & \multirow{2}{*}{$\begin{array}{c}\text { College of Social } \\
\text { Sciences }(\mathbf{N}=391) \\
22.6 \pm 5.17\end{array}$} & \multirow{2}{*}{$\begin{array}{c}\mathbf{p} \\
\\
P= \\
0.272\end{array}$} \\
\hline Age [years] & $x \pm S D$ & & & & & \\
\hline & Median & 22 & 22 & 21 & 22 & \\
\hline & Quartiles & $20-23$ & $20-23$ & $20-23$ & $20-23$ & \\
\hline \multirow[t]{2}{*}{ Gender } & Women & I 23 (76.88\%) & $213(72.45 \%)$ & $|3|(6 \mid .50 \%)$ & 314 (80.3।\%) & $\begin{array}{c}\mathrm{P}< \\
0.00 \mathrm{I}^{*}\end{array}$ \\
\hline & Men & 37 (23.12\%) & 81 (27.55\%) & $82(38.50 \%)$ & 77 (19.69\%) & \\
\hline \multirow[t]{2}{*}{$\begin{array}{l}\text { Social back- } \\
\text { ground }\end{array}$} & Urban & 74 (46.25\%) & 160 (54.42\%) & 73 (34.27\%) & I 78 (45.52\%) & $\begin{array}{c}\mathrm{P}< \\
0.00 I^{*}\end{array}$ \\
\hline & Rural & 86 (53.75\%) & I 34 (45.58\%) & | 40 (65.73\%) & $213(54.48 \%)$ & \\
\hline \multirow{4}{*}{$\begin{array}{l}\text { Religious } \\
\text { commit- } \\
\text { ment }\end{array}$} & Strong & 38 (23.75\%) & 51 (17.35\%) & 37 (17.37\%) & $83(21.23 \%)$ & $\begin{array}{c}P= \\
0.083\end{array}$ \\
\hline & Moderate & 67 (4I.88\%) & $\mid 22$ (4I. $50 \%)$ & 106 (49.77\%) & 189 (48.34\%) & \\
\hline & Weak & 31 (19.38\%) & 75 (25.5।\%) & 35 (16.43\%) & 64 (16.37\%) & \\
\hline & Indifferent & 24 (15.00\%) & 46 (I5.65\%) & 35 (16.43\%) & 55 (14.07\%) & \\
\hline
\end{tabular}

Notes: $\mathrm{p}$ - for quantitative variables Kruskal-Wallis test, for qualitative variables chi-square test or exact Fisher test; *Statistically significant difference $(\mathrm{p}<0.05)$.

0.001). However, in terms of religious commitment, there are no statistically significant differences between these groups $(\mathrm{p}=0.083)$.

Table 2 shows the levels of knowledge and the intensity of attitude of all surveyed respondents toward donation of CP and its implementation in treating COVID-19 patients. The responses were summarized as a knowledge score or attitude score separately. A statistical analysis was done for gender, age, social background and religious commitment. Generally, the surveyed students showed an above-average level of knowledge on the various aspects of the use of $\mathrm{CP}$ in treating patients infected with the SARS-CoV-2 virus $(x=6.43)$. In this respect, women achieved significantly higher results compared to men $(6.57 \pm 1.76$ vs $6.29 \pm 1.84 ; \mathrm{p}=$ $0.034)$. Women also presented more favorable attitudes towards CP donation for COVID-19 patients $(7.34 \pm 2.02$ vs $6.70 \pm 2.35 ; p<0.001)$. The results show that the gender of the respondents is a significant factor influencing their knowledge and attitudes towards this important issue.

Also, the age of the respondents turned out to be a factor that statistically significantly differentiates their knowledge and attitudes towards implementation of $\mathrm{CP}$ in treatment of COVID-19 patients and its donation. The age correlates significantly $(\mathrm{p}<0.05)$ and positively $(r>0)$ both with the knowledge and attitude scores, so the older the age, the higher the knowledge and the more favorable the attitude of the respondents. This relationship turned out to be somewhat unexpected considering the fact that the age differences between the respondents are relatively small. There were no statistically significant differences between the respondents in terms of their social background and religious commitment. Although participants from the urban social environment achieved higher results compared to those from the rural environment, in terms of the level of knowledge (6.59 v. 6.41), the difference between them did not reach the required level of statistical significance $(p=0.280)$. Even smaller differences between the respondents occurred when comparing the results depending on their religious commitment (Table 2).

Table 3 presents the results obtained by students depending on their affiliation to a particular college. The comparison shows that the highest average results regarding knowledge about CP were achieved by students from the College of 
Table 2 Association Between Sociodemographic Characteristics and an Overall Knowledge and Attitudes Results

\begin{tabular}{|c|c|c|c|c|c|c|}
\hline \multirow{2}{*}{\multicolumn{3}{|c|}{ Scores }} & \multicolumn{3}{|c|}{ Gender } & $P$ \\
\hline & & & Women $(N=78 I)$ & Men & $N=277)$ & \\
\hline \multirow{3}{*}{\multicolumn{2}{|c|}{ Knowledge }} & $x \pm S D$ & $6.57 \pm 1.76$ & & \pm 1.84 & $P=0.034^{*}$ \\
\hline & & Median & 7 & & 7 & \\
\hline & & Quartiles & $6-8$ & & $5-8$ & Mann-Whitney test \\
\hline \multirow{3}{*}{\multicolumn{2}{|c|}{ Attitude }} & $x \pm S D$ & $7.34 \pm 2.02$ & & \pm 2.35 & $\mathrm{P}<0.00 \mathrm{I} *$ \\
\hline & & Median & 8 & & 7 & \\
\hline & & Quartiles & $6-9$ & & $5-9$ & \\
\hline \multirow{2}{*}{\multicolumn{3}{|c|}{ Scores }} & \multicolumn{4}{|c|}{ Age } \\
\hline & & & \multicolumn{4}{|c|}{ Spearman Correlation Coefficient } \\
\hline \multicolumn{3}{|l|}{ Knowledge } & \multicolumn{4}{|c|}{$r=0.123, p<0.00 I^{*}$} \\
\hline \multicolumn{3}{|l|}{ Attitude } & \multicolumn{4}{|c|}{$r=0.095, p=0.002 *$} \\
\hline \multirow{2}{*}{\multicolumn{2}{|c|}{ Scores }} & & \multicolumn{3}{|c|}{ Social Background } & $P$ \\
\hline & & & Urban $(\mathrm{N}=485)$ & Rural & $(N=573)$ & \\
\hline \multirow{3}{*}{\multicolumn{2}{|c|}{ Knowledge }} & $x \pm S D$ & $6.59 \pm 1.67$ & & \pm 1.88 & $p=0.280$ \\
\hline & & Median & 7 & & 7 & \\
\hline & & Quartiles & $6-8$ & & $5-8$ & \\
\hline \multirow{3}{*}{\multicolumn{2}{|c|}{ Attitude }} & $x \pm S D$ & $7.15 \pm 2.13$ & & \pm 2.12 & $p=0.779$ \\
\hline & & Median & 8 & & 8 & Mann-Whitney test \\
\hline & & Quartiles & $6-9$ & & $6-9$ & \\
\hline \multirow{2}{*}{\multicolumn{2}{|c|}{ Scores }} & \multicolumn{4}{|c|}{ Religious Commitment } & $P$ \\
\hline & & Strong $(N=209)$ & Moderate $(\mathrm{N}=484)$ & Weak $(N=205)$ & Indifferent $(\mathrm{N}=160)$ & \\
\hline \multirow[t]{3}{*}{ Knowledge } & $x \pm S D$ & $6.33 \pm 1.84$ & $6.46 \pm 1.82$ & $6.59 \pm 1.64$ & $6.68 \pm 1.78$ & $p=0.349$ \\
\hline & Median & 7 & 7 & 7 & 7 & \\
\hline & Quartiles & $6-8$ & $5-8$ & $6-8$ & $6-8$ & \\
\hline \multirow[t]{3}{*}{ Attitude } & $x \pm S D$ & $7.17 \pm 2.18$ & $7.26 \pm 1.96$ & $7.19 \pm 2.15$ & $6.89 \pm 2.49$ & $p=0.893$ \\
\hline & Median & 8 & 8 & 8 & 8 & \\
\hline & Quartiles & $6-9$ & $6-9$ & $6-9$ & $6-9$ & Kruskal-Wallis test \\
\hline
\end{tabular}

Note: *Statistically significant relationship.

Medical Sciences $(\mathrm{x}=7.04)$. The difference turned out to be statistically significant at a high level $(\mathrm{p}<0.001)$. Similar differences between medical students and others occurred in relation to the intensity of attitudes towards donation and the use of CP in the treatment of patients due to COVID-19. Medical students presented more favorable attitudes of this type than representatives of other colleges $(x=7.77)$. Also in this case, the difference turned out to be statistically significant $(\mathrm{p}<0.001)$. The lowest level of the average results related to the knowledge was achieved by students of the College of Social Sciences $(x=6.20)$. Students representing the College of Natural Sciences and the College of Humanities obtained results at an average level, in both the knowledge and attitudes domains. 
Table 3 Comparison of the Results Obtained by Students of Individual Colleges

\begin{tabular}{|c|c|c|c|c|c|c|}
\hline \multicolumn{2}{|l|}{ Scores } & $\begin{array}{l}\text { College of } \\
\text { Humanities - } \\
A(N=160)\end{array}$ & $\begin{array}{l}\text { College of Medical } \\
\text { Sciences - B (N = } \\
294)\end{array}$ & $\begin{array}{l}\text { College of Natural } \\
\text { Sciences - } C(N= \\
213)\end{array}$ & $\begin{array}{l}\text { College of Social } \\
\text { Sciences - D (N = } \\
391)\end{array}$ & $\mathbf{p}$ \\
\hline \multirow[t]{3}{*}{ Knowledge } & $x \pm S D$ & $6.32 \pm 1.84$ & $7.04 \pm 1.47$ & $6.41 \pm 1.94$ & $6.20 \pm 1.81$ & $\mathrm{p}<0.001 *$ \\
\hline & Median & 7 & 7 & 7 & 6 & \\
\hline & Quartile & $5-7$ & $6-8$ & $5-8$ & $5-8$ & $B>C, A, D$ \\
\hline \multirow[t]{3}{*}{ Attitude } & $x \pm S D$ & $6.72 \pm 2.26$ & $7.77 \pm 1.9$ & $7.05 \pm 2.07$ & $6.97 \pm 2.18$ & $\mathrm{p}<0.001 *$ \\
\hline & Median & 7 & 8 & 8 & 8 & \\
\hline & Quartile & $5-9$ & 7-9 & $6-9$ & $6-9$ & $\mathrm{~B}>\mathrm{C}, \mathrm{D}, \mathrm{A}$ \\
\hline
\end{tabular}

Notes: $\mathrm{p}$ - Kruskal-Wallis test + post-hoc analysis (test Dunn test); *Statistically significant relationship.

\section{Discussion}

Since the outbreak of the COVID-19 pandemic, significant efforts have been made around the world to find an effective therapeutic and preventive measures that would stop the development of the infection and the resulting disease. One of them is the use of convalescent plasma collected from fully recovered patients with COVID-19 disease, which is a source of antibodies. Transfusion of plasma or its derived products containing immunoglobulin from patients who have fully recovered from COVID-19 will be a crucial intervention to be used for those who are not able to defend themselves against this pandemic virus, especially in the absence of the relevant vaccine faced in many countries. A systematic review of case reports, case series, observational studies and randomized control trials conducted by Bakhtawar et al between December 2019 and June 2020 showed that plasma therapy produces notable improvements in patients' clinical symptoms and radiological and biochemical parameters associated with COVID-19 infection. The authors emphasize that until we have concrete evidence to prove; otherwise, convalescent plasma therapy may be used as an adjuvant therapy for treating COVID-19 infection in critically ill patients. ${ }^{17}$ Following the initial positive clinical experiences of the use of CP in COVID-19 patients, many European countries and the USA started to organize the collection of hyperimmune plasma to meet current needs and/or to store sufficient numbers of plasma units for future epidemic peaks. ${ }^{18}$ Under these circumstances, much depends on the knowledge and attitudes of potential CP donors. In some countries, such as Italy, there have been dramatic situations due to the lack of CP donors, especially when national law does not provide any compensation for these services. ${ }^{19}$ Based on this example, we understand why currently the collection process and transfusion of plasma derived from patients who have fully recovered from COVID-19 is of widespread interest, both nationally and internationally. Closer understanding of psychological factors, such as the motivation, knowledge and attitudes of potential CP donors, is critical to the success of their recruitment. This is confirmed by preliminary research on targeting and motivating the fully recovered COVID-19 patients to be donors. ${ }^{20}$ The studies conducted so far indicate the existence of a limited number of potential $\mathrm{CP}$ donors in the general population, who differ in many respects from typical blood donors. ${ }^{21}$ However, due to the lack of adequate research on $\mathrm{CP}$ donors, the results obtained in our study must be compared with the results of studies carried out on regular blood donors. ${ }^{22}$

This study was conducted in order to obtain information and inputs from young adults, students of various colleges, which will be useful in implementing relevant donor recruitment strategies because this population can contribute to health-promoting activities in the society. In practice, the hospitals and blood banks have two ways to achieve this goal: 1. to implement traditional policy for effective use of blood, 2. to increase blood donor recruitment by raising awareness of potential donors. ${ }^{22}$ The latter task is related to raising their knowledge to a higher level and shaping attitudes favorable to blood donation.

The results of our study showed that the studied group of young adults has a relatively satisfactory level of knowledge about the treatment of COVID-19 disease with convalescent plasma. Significant differences in the 
results occurred depending on the sex of the respondents. It turned out that women showed a higher level of knowledge about convalescent plasma and its therapeutic and preventive properties compared to men. Also, the age of the respondents turned out to be a factor that significantly determined the level of their knowledge in the discussed area. Older respondents generally presented a wider range of knowledge about convalescent plasma and its possible application in the treatment of patients suffering from COVID-19. This result seems somewhat unexpected, as the respondents only slightly differ in terms of their age of life. This can be explained by the fact that older students had more opportunities to learn about the therapeutic properties of blood plasma, including the COVID-19 convalescent plasma. However, it also turned out that factors, such as the social background of the respondents and their religiosity, did not differentiate between the level of their knowledge about the therapeutic properties of the COVID19 convalescent plasma and the possibility of its donation. Another important factor differentiating the level of knowledge of the respondents turned out to be their affiliation to specific university colleges. As expected, the highest results were achieved by students of the College of Medical Sciences, with women in this group showing a higher level of knowledge than men. The lowest level of knowledge about convalescent plasma was found in a group of students from the College of Social Sciences. These findings are supported by the results of past studies suggesting that there is sufficient basic knowledge regarding the importance of blood donation among medical students. ${ }^{23,24}$ Also, the results of recent studies among Polish medical students showed that they demonstrated a purposeful desire to get vaccinated against SARS-CoV -2, and COVID-19 vaccine conspiracy theories are less popular among them than in group of non-medical students. ${ }^{25}$ For comparison, in another study on attitudes and behaviors towards SARS-CV-2 vaccination among Polish physicians and administrative healthcare assistants it turned out that the latter, in contrast to physicians, expressed their hesitancy to vaccinate. The authors rightly conclude that the fear of COVID-19 vaccine side effects and belief in conspiracy theories are a real threat to the public safety in achieving herd immunity. ${ }^{26}$

The analysis of the results showed a statistically significant relationship between the attitudes towards donation of the COVID-19 convalescent plasma and the gender of the respondents. It turned out that women exhibit more favorable attitudes of this type than men. This result stands somewhat in contrast to that of another study that revealed that the unwillingness to donate blood was more common among the female students and the major reasons were fear and perceived inconvenience, which were associated with blood donation. ${ }^{27}$ Perhaps this difference is due to the fact that the cited studies were conducted in different socio-cultural conditions. In our study, the age of the respondents also modifies their attitude towards the donation of convalescent plasma, while the older respondents show greater motivation in this regard. On the other hand, there was no significant correlation between social background and religious commitment and the intensity of attitudes towards convalescent plasma donation. Nevertheless, there is reason to say that most of our students were willing to donate convalescent plasma, but they had not donated it because of the lack of an opportunity to do so. As compared to a previous study among college students, where there were a high number of respondents with a negative attitude towards blood donation, ${ }^{28}$ in our study, we found an advantage of positive attitudes over negative ones. Our results are in line with many other studies showing that, compared to the general population, university students have a higher level of knowledge and a more positive attitude towards blood donation considering them as an important form of prevention and treatment of many diseases. ${ }^{29-31}$ The course of the COVID-19 pandemic so far shows that it is expected to last a long time. Also so far, there has been a very low rate of donation from people who have been cured of COVID19. In a study by Wang et al in a group of 533 convalescents, it turned out that only one person was willing to donate $\mathrm{CP}$. This happened against the preliminary assumptions of the authors of the research, who expected convalescents to be more motivated to be a donor. However, the practice turned out to be different, as $1 / 3$ of them were not interested in giving $\mathrm{CP}$, many complained of postcomorbid symptoms, and the rest were not enthusiastic about it. ${ }^{21}$ Such studies are very important as the resulting observations could help improve CP donation in current and future pandemics. In the future, efforts to find donors should be based both on providing them with appropriate knowledge and on shaping favorable attitudes. Other factors should also be taken into account because, as is known, blood donation rates are lower for some minority groups due to factors, such as fear, cultural, ethnic and religious beliefs and distrust of medical institutions. ${ }^{32,33}$ It may be suspected that similar factors may also affect potential $\mathrm{CP}$ donors. In order to explain their role, the 
research on the topic we have undertaken should be continued.

Like many others, this study also has some limitations. Firstly, because the study was cross-sectional, a temporal relationship between dependent and independent variables cannot be established. As is known, the true causal relationships among all the identified variables are complex and often reciprocal. Secondly, the surveyed respondents were only university students who may differ from the general population of young adults in Poland, and this would affect the generalizability of the results. Thirdly, the analyzed material does not contain data from students who did not agree to participate in the research, which may induce the possibility of a sampling bias.

\section{Conclusions}

Polish young adults, represented by university students, show a satisfactory level of knowledge relating to the therapeutic and preventive properties of the COVID-19 convalescent plasma. Factors such as gender and age of the respondents are significantly correlated with the level of their knowledge, while their social background and religious commitment do not differentiate them in this respect.

The surveyed university students generally show a sufficient intensity of positive attitude towards CP donation. Attitude scores positively correlated with such sociodemographic characteristics as gender and age of the respondents, with greater intensity of attitudes among women. On the other hand, there was no significant correlation between social background and religious commitment of the respondents and the intensity of attitudes towards CP donation.

The results achieved in this study confirm the need for appropriate health promotional campaigns and educational programs aimed at popularization of $\mathrm{CP}$ donation in the general public, which would increase the chances of involving more patients recovered from COVID-19 disease.

Future research should be more focused on understanding the psychological barriers to CP donation, especially in the group of young adults who have recovered from COVID-19 disease.

\section{Acknowledgments}

The authors would like to thank the students who agreed to participate in this research.

\section{Author Contributions}

Both authors made substantial contributions to conception and design, acquisition of data, or analysis and interpretation of data; took part in drafting the article or revising it critically for important intellectual content; agreed to submit to the current journal; gave final approval for the version to be published; and agreed to be accountable for all aspects of the work.

\section{Funding}

This research was not financially supported by any institution or organization.

\section{Disclosure}

The authors declared no conflicts of interest for this work.

\section{References}

1. Meyerowitz-Katz G, Merone L. A systematic review and meta-analysis of published research data on COVID-19 infection fatality rates. Int $J$ Infect Dis. 2020;101:138-148. doi:10.1016/j. ijid.2020.09.1464

2. Shi Y, Wang Y, Shao C, et al. COVID-19 infection: the perspectives on immune responses. Cell Death Differ. 2020;27(5):1451-1454. doi:10.1038/s41418-020-0530-3

3. ASM Communications. Individual genetic variation in immune system may affect severity of covid-19; 2020. Available from: https:// asm.org/Press-Releases/2020/Individual-Genetic-Variation-inImmune-System-May. Accessed July 28, 2021.

4. Clem AS. Fundamentals of vaccine immunology. $J$ Glob Infect Dis. 2011;3(1):73-78. doi:10.4103/0974-777X.77299

5. Casadevall A, Pirofski L-A. Antibody-mediated regulation of cellular immunity and the inflammatory response. Trends Immunol. 2003;24 (9):474-478. doi:10.1016/S1471-4906(03)00228-X

6. Cunningham AC, Goh HP, Koh D. Treatment of COVID-19: old tricks for new challenges. Crit Care. 2020;24(1):91. doi:10.1186/ s13054-020-2818-6

7. Tortorici MA, Veesler D. Structural insights into coronavirus entry. Adv Virus Res. 2019;105:93-116.

8. Piyush R, Rajarshi K, Khan R, Ray S. Convalescent plasma therapy: a promising coronavirus disease 2019 treatment strategy. Open Biol. 2020;10(9):200174. doi:10.1098/rsob.200174

9. Lanza F, Agostini V, Monaco F, Passamonti F, Seghatchan J. Therapeutic use of convalescent plasma in COVID-19 infected patients with concomitant hematological disorders. Clin Hematol Int. 2021. doi:10.2991/chi.k.210403.001

10. Passamonti F, Cattaneo C, Arcaini L, et al. Clinical characteristics and risk factors associated with COVID-19 disease severity in patients with hematological malignancies in Italy: a multicentre, cohort study. Lancet Haematol. 2020;7:e737-e745. doi:10.1016/ S2352-3026(20)30251-9

11. Brissot E, Labopin M, Baron F, et al. Management of patients with acute leukemia during the COVID-19 outbreak: practical guidelines from the acute leukemia working party of the European society for blood and marrow transplantation. Bone Marrow Transplant. 2021;56:532-535. doi:10.1038/s41409-020-0970-x

12. Wooding DJ, Bach H. Treatment of COVID-19 with convalescent plasma: lessons from past coronavirus outbreaks. Clin Microbiol Infect. 2020;26(10):1436-1446. doi:10.1016/j.cmi.2020.08.005 
13. Lasky B, Goodhue Meyer E, Steele WR, Crowder LA, Young PP. COVID-19 convalescent plasma donor characteristics, product disposition, and comparison with standard apheresis donors. Transfusion. 2021;61(5):1471-1478. doi:10.1111/trf.16286

14. Lanza F, Seghatchain J. Reflection on passive immunotherapy in those who need most: some novel strategic arguments for obtaining safer therapeutic plasma or autologous antibodies from recovered COVID -19 infected patients. Br J Haematol. 2020;190:e1-e38. doi:10.1111/bjh.16814

15. Moniuszko-Malinowska A, Czupryna P, Zarębska-Michaluk D, et al. Convalescent plasma transfusion for the treatment of COVID-19experience from Poland: a Multicenter Study. $J$ Clin Med. 2021;10:28. doi:10.3390/jcm10010028

16. Perenc L, Radochonski M, Radochonska A. Knowledge and attitudes of Polish university students toward organ donation and transplantation. Psychol Health Med. 2012;17(6):667-673. doi:10.1080/13548506.2012.658818

17. Bakhtawar N, Usman M, Khan M. Convalescent plasma therapy and its effects on COVID-19 patient outcomes: a systematic review of current literature. Cureus. 2020;12(8):e9535.

18. Budhai A, Wu AA, Hall L, et al. How did we rapidly implement a convalescent plasma program? Transfusion. 2020;60(7):1348-1355. doi:10.1111/trf.15910

19. Del Fante C, Franchini M, Baldanti F, et al. A retrospective study assessing the characteristics of COVID-19 convalescent plasma donors and donations. Transfusion. 2020;61(3):830-838. doi:10.1111/trf.16208

20. Seghatchian J, Lanza F. Convalescent plasma, an apheresis research project targeting and motivating the fully recovered COVID 19 patients: a rousing message of clinical benefit to both donors and recipients Alice. Transfus Apher Sci. 2020;22:102792. doi:10.1016/j. transci.2020.102792

21. Wang HE, Ostrosky-Zeichner L, Katz J, et al. Screening donors for COVID-19 convalescent plasma. Transfusion. 2021;61 (4):1047-1052. doi:10.1111/trf.16253

22. Allen J, Butler DD. Assessing the effects of donor knowledge and perceived risk on intentions to donate blood. J Health Care Mark. 1993;13:26-33. PMID: 10129813.

23. Juárez-Ocaña S, Pizaña-Venegas JL, Farfán-Canto JM, EspinosaAcevedo FJ, Fajardo-Gutiérrez A. Factors that influence non-donation of blood in relatives of patients at a pediatric hospital. Gac Med Mex. 2001;137:315-322.
24. Sabu KM, Remya A, Binu VS, Vivek R. Knowledge, attitude and practice on blood donation among health science students in a University campus, South India. Online $J$ Health Allied Sci. 2011;10:6

25. Szmyd B, Bartoszek A, Karuga FF, Staniecka K, Błaszczyk M, Radek M. Medical students and SARS-CoV-2 vaccination: attitude and behaviors. Vaccines. 2021;9(2):128. doi:10.3390/ vaccines 9020128

26. Szmyd B, Karuga FF, Bartoszek A, et al. Attitude and behaviors towards SARS-CoV-2 vaccination among healthcare workers: a Cross-Sectional Study from Poland. Vaccines. 2021;9(3):218. doi:10.3390/vaccines9030218

27. Ahmed Z, Zafar M, Khan AA, Anjum MU, Siddique MA. Knowledge, attitude and practices about blood donation among undergraduate medical students in Karachi. J Infect Dis Ther. 2014;2:134. doi:10.4172/2332-0877.1000134

28. Wiwanitkit V. A study on attitude towards blood donation among people in a rural district, Thailand. Southeast Asian J Trop Med Public Health. 2000;31:609-611.

29. Hosain GM, Anisuzzaman M, Begum A. Knowledge and attitude towards voluntary blood donation among Dhaka University students in Bangladesh. East Afr Med J. 1999;74:549-553.

30. Mwaba K, Keikelame MJ. Blood donation behaviour and beliefs among a sample of high school students in Mmabatho. Curationis. 1995;18:2-3. doi:10.4102/curationis.v18i3.1356

31. Wiwanitkit V. Knowledge about blood donation among a sample of Thai university students. Vox Sang. 2002;83(2):97-99. doi:10.1046/ j.1423-0410.2002.00209.x

32. Patel EU, Bloch EM, Grabowski MK, et al. Sociodemographic and behavioral characteristics associated with blood donation in the United States: a population-based study. Transfusion. 2019;59 (9):2899-2907. doi:10.1111/trf.15415

33. Spratling R, Lawrence RH. Facilitators and barriers to minority blood donations: a systematic review. Nurs Res. 2019;68(3):218-226. doi:10.1097/NNR.0000000000000355
Journal of Blood Medicine

\section{Publish your work in this journal}

The Journal of Blood Medicine is an international, peer-reviewed, open access, online journal publishing laboratory, experimental and clinical aspects of all aspect pertaining to blood based medicine including but not limited to: Transfusion Medicine; Blood collection, Donor issues, Transmittable diseases, and Blood banking logistics; Immunohematology; Artificial and alternative blood based therapeutics; Hematology; Biotechnology/nanotechnology of blood related medicine; Legal aspects of blood medicine; Historical perspectives. The manuscript management system is completely online and includes a very quick and fair peer-review system. Visit http://www.dovepress.com/testimonials.php to read real quotes from published authors. 